\title{
A educação sexual na escola católica
}

Humberto Robson de Carvalho*

\section{Resumo}

A sexualidade, compreendida no seu aspecto mais profundo e complexo, expressa o ser integral de cada pessoa. É parte fundamental da experiência como fonte de prazer, realização emocional e estruturação de identidade, permeando o ser humano desde o nascimento até a morte. Considerando os aspectos biológicos, psicológicos, socioculturais e filosóficos da sexualidade humana, pode-se compreendê-la de maneira mais eficaz e abrangente.

Revelando tais aspectos, esta pesquisa tem por objetivo identificar "o quê" e "como" os alunos de primeiro ano do ensino médio de uma escola católica de São Paulo querem aprender ou aprofundar seus conhecimentos sobre sexualidade.

* Excerto de Tese de Mestrado. Trabalho vencedor do Prêmio SBRASH na categoria Educação Sexual $-8^{\alpha}$ Congresso Brasileiro de Sexualidade Humana.

** Sacerdote, graduado em Filosofia, Pedagogia e Teologia, Educador Sexual e Mestre em Educação. Pároco da Paróquia São Francisco Xavier. 
A investigação dessa pesquisa se delineia como um estudo de caso. A verificação foi possibilitada através da aplicação de um questionário a 96 alunos na faixa etária entre 14 e 15 anos na cidade de São Paulo.

Palavras-chaves: sexualidade, educação sexual, educando e escola católica.

\section{Summary}

Sexuality, as understand its most profound complexity, expresses the integrity of all human beings. Experience teaches us that sexuality gives pleasure, offers emotional feelings and lead to full realization of the individual. Considering it from all aspects: biological, psychological, social and philosophical, one can understand its importance and necessity. Presenting sexuality in this way, the another of this work wants to identify "what" and "how" the students of the first year of a secondary catholic school have to understand and know more about sexuality.

The result of this work was obtnainned by studing special cases. It has been proved out that, after reading the results of a questionaire with 96 students from São Paulo, aged 14 and 15 years.

\section{Introdução}

A sexualidade humana expressa e realiza o ser integral de cada pessoa. Faz parte das experiências do cotidiano como fonte de prazer, realização emocional e estruturação de identidade.

No trabalho de Freud é revelada a interferência da sexualidade no "desejo de saber". Para ele "a mola" propulsora do desenvolvimento intelectual é a energia libidinal, oriunda dos impulsos sexuais que não conseguem, nos primeiros anos de vida, satisfazerem-se na forma genital (Kupfer, 1995, p. 84).

Dificuldades na vida afetiva-sexual podem comprometer o desenvolvimento psicológico dos jovens e bloquear seu processo de aprendizagem. Sendo esta uma questão relevante à formação dos seres humanos, é natural que mereça atenção no ensino escolar.

A dimensão sociocultural da sexualidade tem despertado nos pesquisadores grande interesse nas diversas áreas do conhecimento, comenta Fagundes (1996, p. 131).

Entende-se por "educação sexual" o processo de vida envolvendo informações recebidas e aprendidas sobre sexualidade, de modo especial, na família. Esse processo se realiza muitas vezes sem se perceber. Ocorre de maneira informal. É através do relacionamento afetuoso com os pais que a criança adquire a capacidade amorosa e erótica da sexualidade que amadurecerá durante a vida. 
Apesar de muitos especialistas sobre esse assunto preferirem a expressão "orientação sexual", esse trabalho adota a terminologia "educação sexual" como mais adequada. A expressão "educação sexual" está sendo preferida, principalmente, pelo seu sentido de maior abrangência e profundidade. Entende-se que educação envolve orientações, mas que nem toda orientação é necessariamente educativa.

A educação sexual é toda ação de ensino - aprendizagem sobre a sexualidade humana, envolvendo conhecimento mas também discussões e reflexões sobre valores, normas, sentimentos, emoções e atitudes relacionadas à vida sexual. Assim, a educação sexual deve considerar o educando como sujeito ativo no processo de aprendizagem e não apenas receptor de conhecimentos, informações ou orientações (Figueiró, 1996, p. 17).

Acompanhando a trajetória dos estudantes, bem como os seus anseios e angústias percebem-se a necessidade de um acompanhamento sistemático e humanizante no que se concerne à educação sexual. A necessidade dessa abordagem é defendida, entre outros, por Vitiello (1995, p. 23-4), que valoriza, na educação sexual, o objetivo da promoção da felicidade, preparando os jovens para o sexo responsável, como fonte de realização pessoal e coletiva.

Pressupõe-se que os aspectos antropológicos e socioculturais são fundamentais no desenvolvimento integral dos seres humanos, por isso, podese afirmar que a sexualidade humana transcende ao biológico e psicológico (Mota, 1996, p. 185). É parte integral da vida das pessoas e está estreitamente ligada com as relações interpessoais e com a estrutura social, o que também é prioridade na educação escolar.

A abordagem teórico-metodológica tem, nessa pesquisa, como ponto de partida, o ser humano. Nenhuma outra realidade apaixona tanto como a questão do ser humano. Cabe ressaltar nessa consideração o princípio do sofista Pitágoras: o ser humano é a medida de todas as coisas.

Ressalta-se a preocupação científica em sintonia com a necessidade de transcender a realidade, uma vez que o autor dessa pesquisa como tantos outros educadores, está inconformado com a situação pela qual a sexualidade vem sendo apresentada.

Espera-se que os apontamentos feitos possam incentivar os jovens educandos, oferecendo-lhes uma visão amorosa da sua sexualidade bem como contribuir para o avanço científico de trabalhos e pesquisas sobre educação sexual nas escolas católicas.

\section{Metodologia}

A investigação relatada se delineia como um estudo de caso, pois foi selecionada uma escola católica como objeto de estudo.

Os sujeitos da pesquisa foram os alunos do primeiro ano do ensino médio em uma escola católica. A pesquisa foi realizada durante o segundo semestre do ano letivo de 1999.Todos esses estudantes residem na zona leste 
da cidade de São Paulo. A média de idade varia entre 14 e 15 anos. Os alunos, em sua grande maioria, residem nas proximidades da escola, pertencem à classe média e professam a religião católica. No total somam 96 alunos.

Para a análise dos dados os alunos foram subdivididos em três grupos, a fim de perceber com mais precisão "o quê" e "como" os jovens querem aprender sobre a sexualidade no ensino escolar. Concorda-se com Ribeiro (2000, p. 18) quando afirma que nem sempre o melhor aluno é aquele que ostenta as melhores notas. No entanto, para facilitar o desenvolvimento da pesquisa utilizar-se-á o critério de classificação apenas como referência. Essa distribuição foi elaborada em conjunto com a orientadora educacional e coordenadora pedagógica da escola em questão.

Os alunos foram assim distribuídos:

G1: alunos com desempenho escolar bom/satisfatório. Do total dos 96 alunos, foram 57 os classificados para esse grupo. Sendo 22 do sexo masculino e 35 do sexo feminino.

G2: alunos com defasagem escolar. Do total dos 96 alunos, foram 15 os classificados para esse grupo. Sendo 6 do sexo masculino e 9 do sexo feminino.

G3: alunos com defasagem escolar e dificuldade disciplinar e/ou no relacionamento no meio escolar. Dos 96 alunos, foram 24 os classificados para esse grupo. Sendo 13 do sexo masculino e 11 do sexo feminino.

\section{Análise dos resultados}

Os resultados sobre "o quê" e "como" os jovens querem aprender ou aprofundar sobre a sexualidade no ensino escolar foram classificados e tabulados tendo como parâmetro e referencial teórico o Guia de Orientação Sexual, escolha feita pela sua seriedade, pela sua visão e pela competência dos profissionais que nele trabalharam, além de ser um ponto de referência obrigatória e atual da educação em termos de sexualidade humana. O guia foi elaborado em 1994 pelo Fórum Nacional de educação e sexualidade por renomados especialistas na área da educação, da psicologia e da educação sexual. 
Tabela 1 - Freqüência de respostas sobre assuntos que os alunos gostariam de aprender ou aprofundar a respeito da sexualidade.

\begin{tabular}{|c|c|c|c|c|c|c|c|c|c|c|c|c|}
\hline \multicolumn{2}{|c|}{ Categorias e sub-categorias de assuntos } & \multicolumn{3}{|c|}{$\underset{(n=57)}{\text { Grupo } 1}$} & \multicolumn{5}{|c|}{$\underset{(n=15)}{\text { Grupo 2 }} \quad \underset{(n=24)}{\text { Grupo } 3}$} & \multicolumn{3}{|c|}{ TOTAIS } \\
\hline & & $\begin{array}{l}\text { M I } \\
223\end{array}$ & $\begin{array}{cc}\text { F } \\
35\end{array}$ & T $\mathrm{N}$ & $\begin{array}{cc}\text { M } & \text { F } \\
6 & 9\end{array}$ & $\begin{array}{ll}\mathbf{F} & \mathbf{T} \\
9 & \end{array}$ & & & T $\begin{array}{r}N \\
4\end{array}$ & $\begin{array}{lc}\text { M } & \text { F } \\
41 & 55\end{array}$ & & \\
\hline \multirow{3}{*}{ 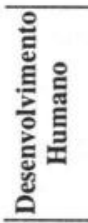 } & $\begin{array}{l}\text { Anatomia e Fisiologia Reprodutiva } \\
\text { Reprodução }\end{array}$ & 1 & 1 & 2 & & & & & & 1 & & 2 \\
\hline & Puberdade & 1 & & 1 & & & & 1 & 1 & 1 & & 2 \\
\hline & $\begin{array}{l}\text { Corpo e Auto-Estima } \\
\text { Atração Hetero, Homo e Bissexual }\end{array}$ & & 1 & 1 & & 1 & 1 & & & 2 & & 2 \\
\hline \multirow[t]{2}{*}{ 总 } & $\begin{array}{l}\text { Família } \\
\text { Amizade } \\
\text { Amor } \\
\text { Namoro e Relacionamentos Eventuais } \\
\text { Casamento e União Estável }\end{array}$ & 1 & & 1 & & & & & & 1 & & 1 \\
\hline & Paternidade / Maternidade & 51 & 111 & 16 & & 99 & 3 & 3 & 6 & 823 & & 31 \\
\hline \multirow[t]{2}{*}{ 胥 } & $\begin{array}{l}\text { Valores } \\
\text { Decisões } \\
\text { Comunicação } \\
\text { Assertividade } \\
\text { Negociação } \\
\text { Busca de Ajuda }\end{array}$ & & & & & & & & & & & \\
\hline & Busca de Ajuda & & 1 & 1 & & & & & & 1 & & 1 \\
\hline \multirow{3}{*}{ 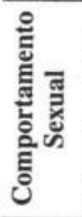 } & $\begin{array}{l}\text { Sexualidade ao Longo da Vida } \\
\text { Masturbação } \\
\text { Vida Sexual Compartilhada }\end{array}$ & 41 & 151 & 19 & 12 & 23 & 2 & 5 & 7 & 722 & & 29 \\
\hline & $\begin{array}{l}\text { Desejo e Prazer Sexual } \\
\text { Fantasia }\end{array}$ & 23 & 3 & 5 & & & & & & 2 & & 5 \\
\hline & Disfunção Sexual & 1 & & 1 & & & & & & 1 & & 1 \\
\hline \multirow{5}{*}{ 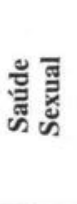 } & Métodos Anticoncepcionais & 5 & 6 & 11 & 1 & 12 & 1 & 2 & 37 & 7 & & 16 \\
\hline & Aborto & & 4 & 4 & & 11 & & & & & & 5 \\
\hline & DST's e Infecção pelo HIV & 192 & 274 & 46 & 4 & $\begin{array}{ll}9 & 1\end{array}$ & 1312 & 12 & 243 & 3548 & & 83 \\
\hline & $\begin{array}{l}\text { Práticas de Sexo Protegido } \\
\text { Abuso Sexual }\end{array}$ & 53 & 3 & 8 & 2 & 13 & 31 & 2 & 38 & 86 & 6 & 14 \\
\hline & Saúde Reprodutiva & & 1 & 1 & & & & 1 & 1 & 2 & & 2 \\
\hline 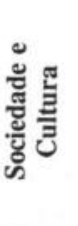 & $\begin{array}{l}\text { Sexualidade e Sociedade } \\
\text { Relações de Gênero } \\
\text { Sexualidade, Direito e Cidadania } \\
\text { Sexualidade e Religião } \\
\text { Diversidade } \\
\text { A Sexualidade e a Mídia } \\
\text { A Sexualidade e as Artes }\end{array}$ & & & & & & & & & & & \\
\hline
\end{tabular}


Nas categorias:

Desenvolvimento humano, a pesquisa demonstra percentuais poucos significativos.

Relacionamento, o G1 desenvolve dois assuntos: família, que demonstra ser pouco importante em relação a educação sexual e paternidade/maternidade responsável sendo na maioria mencionado pelas meninas. O mesmo ocorre com o G2, porém, com um percentual maior. Coincide também com o G3, apresentando uma diferença de percentual da paridade masculino/feminino.

Comunicação, só o G1 faz alusão a um assunto. Uma resposta feminina. Busca de ajuda.

Comportamento sexual, o G1 novamente aparece com um número maior de assuntos. $\mathrm{O}$ grupo demonstra maior clareza em apontar uma série de assuntos. É a segunda vez que o grupo apresenta três alternativas. $\mathrm{O}$ único assunto tratado pelo G2 nessa categoria coincide no assunto com o G1, porém num percentual menor. O G2 e o G3 apresentam indicações semelhantes ao assunto sexualidade ao longo da vida. Percebe-se que é o único assunto em que os três grupos coincidem. $\mathrm{O}$ número feminino é superior nos três grupos. Os assuntos sobre comportamento apresentam índices maiores que os assuntos anteriores.

Saúde sexual, supera as anteriores, inclusive a do comportamento sexual. Aqui os grupos apresentam números maiores.

É nessa categoria que os alunos têm uma manifestação maior. No G2 o número é maior nos assuntos e nos percentuais. A manifestação foi maior e os assuntos 4 no total deste grupo, coincidem com 4 dos 5 trabalhados pelo G1 e com 3 dos 4 trabalhados no G2.

O que chama atenção nessa pesquisa é a abstenção total dos três grupos na categoria sociedade e cultura. Esse aspecto da abstenção merece posterior reflexão, pois pode ser forte indicativo da necessidade de tratá-la de forma mais existencial e menos abstrata.

Comunicação é segunda na ordem das variáveis crescentes, teve uma única resposta.

Relacionamentos, terceira no número de variáveis, na ordem crescente com dois assuntos: família e paternidade/maternidade responsável.

Desenvolvimento humano e relacionamentos ocupam o quarto lugar e têm igual número de variáveis, porém, diferentes nos percentuais.

Comportamento sexual é a quinta na ordem crescente. Apesar de os grupos manifestarem três assuntos referentes a essa categoria a temática não demonstra grande importância por parte dos estudantes.

No que se refere ao "como" da pesquisa (cf. Tabela 2), segundo a frequêencia das respostas a palestra é a maneira preferida pelos estudantes dos três grupos para que a escola desenvolva atividades em questão.

Percebe-se que os grupos que mais se aproximam entre si são o G1 e o G3. Concluiu-se que pode ser feito pelo tipo de características dos mesmos em relação à classificação elaborada. Muito embora essa referência não seja uma determinante, apenas um elemento classificatório. 
Pode-se observar que o número feminino é maior, exceto na última categoria. Nota-se que o "como" precisa ser visto também em função das categorias, tal como foi analisado e apresentado.

Mesmo sendo a palestra a maneira preferida pelos estudantes dos três grupos, é um indicativo e ao mesmo tempo um alerta, pelo fato de os educandos quererem romper com a aula clássica e inclusive apontando para o fato de serem feitas por especialistas da área, demonstrando a necessidade de introduzir pessoas novas diferentes e mesmo novas técnicas pedagógicas; por outro lado, o esquema de palestra já é bastante conhecido no contexto escolar. De qualquer forma, parece que os alunos ainda tendem a se colocar no papel passivo, reproduzindo um modelo em que a significação do aprendizado se dá a partir da escuta pouco participativa, e da delegação ao professor dos status de alguém dotado de um "saber legítimo" a respeito da temática versada.

Tabela 2 - Freqüência de respostas sobre a maneira pela qual os alunos gostariam que a escola desenvolvesse as atividades sobre educação sexual.

\begin{tabular}{|c|c|c|c|c|c|c|c|c|c|c|c|c|}
\hline \multirow[t]{2}{*}{ Respostas } & \multicolumn{9}{|c|}{ GRUPO 1 GRUPO 2 GRUPO 3} & \multicolumn{3}{|c|}{ TOTAL } \\
\hline & M & $\mathbf{F}$ & $\mathbf{T}$ & $\mathbf{M}$ & $\mathbf{F}$ & $\mathbf{T}$ & $\mathbf{M}$ & $\mathbf{F}$ & $\mathbf{T}$ & M & $\mathbf{F}$ & $\mathbf{T}$ \\
\hline 1. Palestra & 11 & 27 & 38 & 6 & 8 & 14 & 8 & 9 & 17 & 25 & 44 & 69 \\
\hline 2. Aula & 13 & 24 & 37 & 1 & 8 & 9 & 9 & 9 & 18 & 23 & 41 & 64 \\
\hline 3. Aconselhamento & 5 & 5 & 10 & - & 3 & 3 & 3 & 2 & 5 & 8 & 10 & 18 \\
\hline 4. Orientação individual & 3 & 6 & 9 & - & 1 & 1 & 2 & 1 & 3 & 5 & 8 & 13 \\
\hline 5. Curso & 1 & 3 & 4 & - & 1 & 1 & 2 & 2 & 4 & 3 & 6 & 9 \\
\hline 6. Vídeos & 1 & 1 & 2 & - & - & - & 1 & - & 1 & 2 & 1 & 3 \\
\hline 7. Exposições & - & - & - & - & 1 & 1 & - & - & - & - & 1 & 1 \\
\hline 8. Jogos & - & - & - & - & 1 & 1 & - & - & - & - & 1 & 1 \\
\hline 9. Linguagem descontraída & - & 1 & 1 & - & - & - & - & - & - & - & 1 & 1 \\
\hline 10. Livros & - & - & - & - & - & - & - & 1 & 1 & - & 1 & 1 \\
\hline 11. Trazer pessoas com doenças & 1 & - & 1 & - & - & - & - & - & - & 1 & - & 1 \\
\hline Total & 35 & 67 & 102 & 7 & 23 & 30 & 25 & 24 & 49 & & & \\
\hline
\end{tabular}

Observa-se que o G1 e o G3 são os que têm uma aproximação ou identidade maior, talvez, pelo tipo de características no que diz respeito à classificação elaborada. Mesmo não sendo a classificação uma fórmula de rótulo ou maneira de enxergar o aluno na sua totalidade. 
A pesquisa, como recurso pedagógico, permite identificar "o quê" e "como" os educandos precisam ser elucidados dentro da amplitude do assunto sexualidade. Esse processo oferece, nas entrelinhas e também na transversalidade, a possibilidade de detectar a necessidade de ser inter e trans-disciplinar, já que a educação sexual pode ser um pretexto para educar.

\section{Conclusões e recomendações}

A sexualidade humana, reconhecida como dimensão essencial da criatura humana, é valorizada neste trabalho como parte integrante da realidade existencial de cada um. Compreende-se a sexualidade não apenas como expressão do corpo biológico, mas expressão máxima do ser que deseja, que acolhe, que ama, que se solidariza, que se comunica com os outros em busca de identidade e complementaridade.

Sabe-se também que a sexualidade humana requer um tratamento sério e competente da família e da escola. Essa constatação exige que mais pessoas estejam efetivamente preparadas para lidar com o assunto.

Analisando as respostas dos alunos, percebe-se que a categoria desenvolvimento humano apresenta um certo vazio. Deduz-se desintegração de informação e ou descontextualização dos conhecimentos. Vale a pena refletir se os conteúdos apresentados nas diversas disciplinas da área humanista têm conseguido abranger os aspectos fundamentais da formação integral do educando.

No que se refere a relacionamentos, o vazio é ainda maior. Esse aspecto, no que diz respeito à sexualidade, deixa evidente que os estudantes pesquisados não percebem sua dimensão ou ainda não conseguem fazer nenhuma correlação entre sexualidade e relacionamento.

A categoria comunicação aparece quase vazia. Atualmente, na busca do ser feliz e realizado, não se concebe tal descaso, porém, deduz-se que os educandos ainda não conseguem associar sexualidade com comunicação. A comunicação parece não se relacionar com o seu comportamento e a busca de vivência da sexualidade.

Já comportamento sexual foi mais abordado, mas se vê que os percentuais são poucos significativos. Pode-se afirmar que tais manifestações comportamentais são importantes para os adultos e ainda não captadas pelos jovens. Tratando-se de "comportamento" era de se esperar uma manifestação mais ampla.

Considerando saúde sexual com maior número de respostas, deduz-se que existe um nível maior de informação ou interesse por parte dos alunos. 
No entanto, restam dúvidas importantes em relação a algumas questões como abuso sexual, saúde reprodutiva e aborto.

Sociedade e cultura foi a única categoria que não obteve nenhuma resposta. Não interessa? Desconhecem? Não se associa o peso, as exigências culturais à sua formação? Ignoram a contextualização sociocultural? As disciplinas como educação artística, comunicação e expressão, ensino religioso, filosofia, psicologia não estão relacionadas com educação sexual? Cabe aqui uma análise e reflexão do papel da escola católica no que se refere à formação integral do educando e na possibilidade de trabalhar com mais eficiência os temas desenvolvidos pelas diversas disciplinas contextualizando a sexualidade humana nos variados aspectos da vida e da aprendizagem.

No que se refere ao "como", a palestra, apesar de ser uma estratégia diferente, permite o silêncio e inclusive o anonimato.

Ao definir o tema da pesquisa, o autor quis focalizar alguns dos diversos aspectos que a sexualidade apresenta, considerando a sexualidade como dom, compromisso, felicidade e prazer, bem como orientar uma proposta de ensino escolar sobre sexualidade humana, apresentando os anseios e expectativas dos jovens à luz da antropologia cristã.

Mediante os resultados, evidencia-se a grande utilidade da aplicação dos conhecimentos adquiridos nessa investigação, por isso recomenda-se:

- acreditar que a sexualidade humana é sinal de vida e esperança. É dom que promove compromisso, felicidade, realização e prazer.

- ser consciente de que os encontros de educação sexual não podem se restringir à incorporação de receitas prontas. Elas envolvem a pesquisa, a busca, o embasamento teórico e ainda abertura para os temas sugeridos pelos alunos.

- possibilitar a formação dos educadores nos cursos de preparação de professores ou fora deles.

- permitir a formação e a integração dos pais nos assuntos que se referem à sexualidade. À escola cabe, portanto, auxiliar a família na tarefa de educar para sexualidade e não substituí-la.

- organizar os encontros de educação sexual de forma interdisciplinar.

- valorizar a educação sexual na escola como instrumento indispensável para propiciar aos educandos uma formação responsável, consciente, segura, solidária e libertadora que possa proporcionar uma aprendizagem para vivência da sexualidade plena e feliz. 


\section{Referências Bibliográficas}

FAGUNDES, T. C. P. C. Implantação da disciplina de sexualidade e educação na Universidade da Bahia. Revista Brasileira de Sexualidade humana. São Paulo: Iglu, n. 7 ed. Especial (2) p. 131, 1996.

FIGUEIRÓ, M. N. D. Educação sexual: retomando uma proposta, um desafio. Londrina: Editora Uel, 1996.

FORUM N. E. S. Guia de orientação sexual. Diretrizes e metodologia. São Paulo: Casa do Psicólogo Livraria e Editora Ltda, 1994.

KUPFER, M. C. Freud e a educação. O mestre do impossível. São Paulo: Scipione, 1995.

MOTA, M. V. S. A. A sexualidade silenciada na escola: implicações da orientação sexual subjacente no cotidiano escolar. Revista Brasileira de Sexualidade Humana. São Paulo: Iglu, n. 7, ed. especial 2. p. 185-9, 1996.

RIBEIRO, N. As aparências se enganam. Revista Educação. São Paulo: Editora Segmento, ano 26, n. 225: p. 18, 2000.

VITIELLO, N. A educação sexual necessária. Revista Brasileira de Sexualidade Humana. São Paulo: Iglu, n. 6, v. 1. p. 23-4, 1995. 